SUPPORTING INFORMATION

\title{
Relating Geometric Nanoconfinement and Local Molecular Environment to Diffusion in Ionic Polymer Membranes
}

\author{
Rui Zhang ${ }^{1}$, Ying Chen ${ }^{2}$, Diego Troya ${ }^{1}$, and Louis A. Madsen ${ }^{1} *$
}

\begin{abstract}
${ }^{1}$ Department of Chemistry and Macromolecules Innovation Institute, Virginia Polytechnic Institute and State University, Blacksburg, VA 24061

${ }^{2}$ Physical \& Computational Sciences Directorate, Pacific Northwest National Laboratory, Richland, WA 99345
\end{abstract}

\section{Corresponding authors}

*Louis A. Madsen

Virginia Tech

Blacksburg, VA 24061

$\underline{\text { lmadsen@vt.edu }}$

*Diego Troya

Virginia Tech

Blacksburg, VA 24061

troya@ vt.edu 


\section{Experimentally measured $D$ and $E_{a}$ of bulk liquid water and water in membrane}

\begin{tabular}{|c|c|c|c|c|c|c|c|}
\hline \multicolumn{3}{|c|}{ LiOTf solution } & \multicolumn{3}{|c|}{ Nafion membrane } & \multicolumn{2}{|c|}{ Bulk liquid water } \\
\hline$\lambda$ & $\begin{array}{c}\text { D at } 30^{\circ} \mathrm{C} \\
\left(\times 10^{-9} \mathrm{~m}^{2} / \mathrm{s}\right)\end{array}$ & $\begin{array}{c}\mathbf{E}_{\mathrm{a}} \\
(\mathbf{k J} / \mathbf{m o l})\end{array}$ & $\lambda$ & $\begin{array}{c}\text { D at } 30{ }^{\circ} \mathrm{C} \\
\left(\times 10^{-10} \mathrm{~m}^{2} / \mathrm{s}\right)\end{array}$ & $\begin{array}{c}\mathbf{E}_{\mathrm{a}} \\
(\mathbf{k J} / \mathbf{m o l})\end{array}$ & $\begin{array}{c}\text { D at } 30{ }^{\circ} \mathrm{C} \\
\left(\times 10^{-9} \mathrm{~m}^{2} / \mathrm{s}\right)\end{array}$ & $\begin{array}{c}\mathbf{E}_{\mathrm{a}} \\
(\mathrm{kJ} / \mathbf{m o l})\end{array}$ \\
\hline 3.0 & 0.190 & 25.4 & 2.5 & 0.0197 & 39.5 & 2.62 & 18.5 \\
\hline 4.0 & 0.333 & 24.0 & 3.0 & 0.0763 & 35.2 & & \\
\hline 5.0 & 0.464 & 23.7 & 3.5 & 0.233 & 31.0 & & \\
\hline 6.1 & 0.626 & 22.9 & 4.9 & 0.701 & 24.6 & & \\
\hline 8.7 & 0.937 & 22.5 & 6.6 & 1.51 & 23.4 & & \\
\hline 12 & 1.21 & 22.4 & 9.7 & 3.14 & 21.7 & & \\
\hline 15 & 1.37 & 22.1 & 14 & 4.70 & 19.8 & & \\
\hline 21 & 1.52 & 20.8 & 20 & 6.81 & 19.5 & & \\
\hline
\end{tabular}

\section{Force field parameters for lithium triflate and PSFA sidechain}
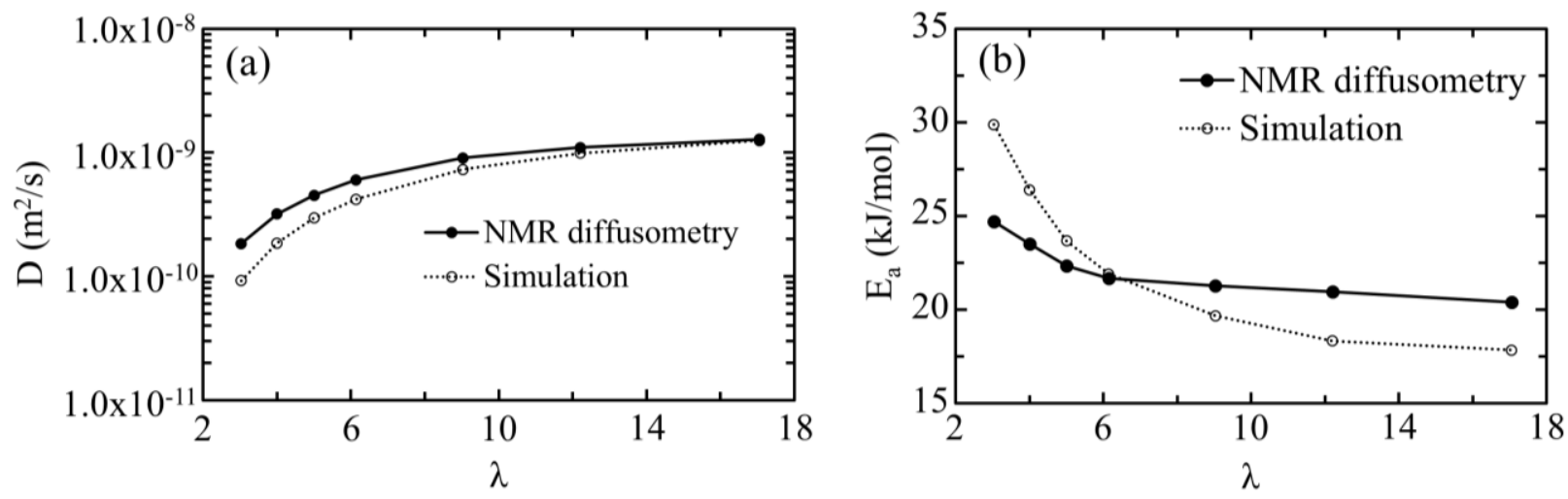

Figure S1. Parallel comparison between NMR and simulation results. $D_{\text {water }}$ in LiOTf solutions at $300 \mathrm{~K}$ (a) and $E_{a}$ of diffusion (b) as a function of hydration level. The range of $\lambda$ is based on the hydration range of Nafion membrane and the solubility of LiOTf. We focused on fixed-charged force fields in this work. These results display optimum diffusion coefficients obtained from our optimization approach. The simulations predict slightly larger activation energies and lower diffusion coefficients at low $\lambda$, which is consistent with the overestimation of electrostatic interactions by fixed-charged MD simulations. All attempts to better match the low- $\lambda$ region of the activation energy curve resulted in a degradation of the agreement with experimental diffusion coefficients at intermediate and high hydration levels. Even 
though the experimental activation energy as a function of hydration is not quantitatively matched by the calculations, the force field nicely reproduces the trend, which lends confidence on the qualitative insight we gained with the rest of simulations.

\section{2a. Force field parameters for lithium triflate}

Table S2. Lennard Jones parameters and charges

\begin{tabular}{cccc}
\hline Atom & $\boldsymbol{\sigma}(\mathbf{n m})$ & $\boldsymbol{\varepsilon}\left(\mathbf{k J ~ m o l} \mathbf{~}^{\mathbf{1}}\right)$ & $\mathbf{q}$ \\
\hline $\mathrm{C}$ & 0.350 & 0.276144 & 0.36 \\
$\mathrm{~F}$ & 0.295 & 0.221752 & -0.12 \\
$\mathrm{~S}$ & 0.355 & 1.406 & 0.20 \\
$\mathrm{O}$ & 0.296 & 0.71128 & -0.40 \\
$\mathrm{Li}$ & 0.212645 & 0.764793 & 1.00 \\
\hline
\end{tabular}

Table S3. Bond parameters

\begin{tabular}{ccc}
\hline Atom pair & Bond length $(\mathbf{n m})$ & Force constant $\left(\mathbf{k J ~} \mathbf{~ m o l}^{\mathbf{- 1}} \mathbf{~ m}^{-\mathbf{2}}\right)$ \\
\hline $\mathrm{C}-\mathrm{F}$ & 0.1332 & 307105.6 \\
$\mathrm{C}-\mathrm{S}$ & 0.1810 & 185769.6 \\
$\mathrm{~S}-\mathrm{O}$ & 0.1440 & 585760 \\
\hline
\end{tabular}

A harmonic bond potential is used

$$
V_{b}=\frac{1}{2} k\left(r-b_{0}\right)^{2}
$$

where $V_{b}$ is the bond potential, $\mathrm{k}$ is the force constant, $\mathrm{r}$ is the actual bond length, and $b_{0}$ is the equilibrium bond length.

Table S4. Bond angle parameters

\begin{tabular}{ccc}
\hline & Angle $(\mathbf{d e g})$ & Force constant $\left(\mathbf{k J ~ m o l}^{\mathbf{- 1}} \mathbf{~ r a d}^{-\mathbf{2}}\right)$ \\
\hline $\mathrm{F}-\mathrm{C}-\mathrm{F}$ & 109.1 & 644.336 \\
$\mathrm{O}-\mathrm{S}-\mathrm{O}$ & 119 & 870.272 \\
$\mathrm{~F}-\mathrm{C}-\mathrm{S}$ & 109.8 & 418.4 \\
$\mathrm{C}-\mathrm{S}-\mathrm{O}$ & 95.77 & 619.323 \\
\hline
\end{tabular}

A harmonic angle potential is used

$$
V_{a}=\frac{1}{2} k\left(\theta-\theta_{0}\right)^{2}
$$

where $V_{a}$ is the angle potential, $\mathrm{k}$ is the force constant, $\theta$ is bond angle, and $\theta_{0}$ is equilibrium bond angle. 
Table S5. Dihedral parameters

\begin{tabular}{cccc}
\hline & $\varphi_{\mathbf{0}}$ & Force constant $\left(\mathrm{kJ} \mathrm{mol}^{\mathbf{- 1}}\right)$ & Multiplicity \\
$\mathbf{F}-\mathbf{C}-\mathbf{S}-\mathbf{O}$ & 0 & 17.00 & 3 \\
\hline
\end{tabular}

A periodic dihedral function is used

$$
V_{\text {dihe }}=k\left(1+\cos \left(n \varphi-\varphi_{0}\right)\right.
$$

Where $V_{\text {dine }}$ is the potential energy, $\mathrm{k}$ is the force constant, $\mathrm{n}$ is the multiplicity, $\varphi$ is the angle between the $\mathrm{F}-\mathrm{C}-\mathrm{S}$ and $\mathrm{C}-\mathrm{S}-\mathrm{O}$ planes.

\section{2b. Force field parameters for the Nafion sidechain}

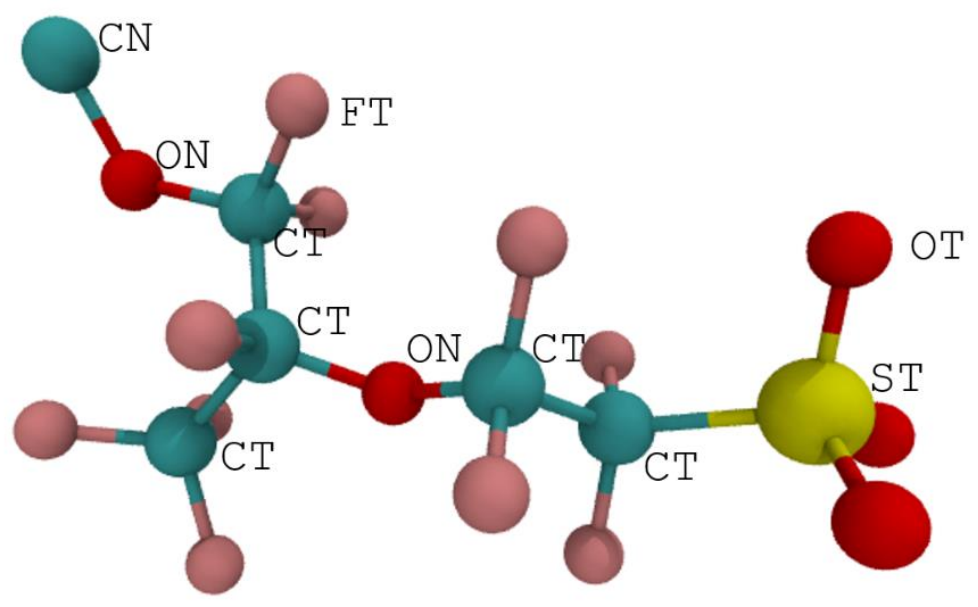

Figure S2. Atom name description of the Nafion sidechain model. Note there are different types of oxygen atoms and carbon atoms.

Table S6. Lennard Jones parameters and charges

\begin{tabular}{cccc}
\hline Atom name & $\boldsymbol{\sigma}(\mathbf{n m})$ & $\boldsymbol{\varepsilon}\left(\mathbf{k J ~ m o l}^{\mathbf{- 1}}\right)$ & $\mathbf{q}$ \\
\hline CN & 0.355 & 0.29288 & 0.00 \\
ON & 0.300 & 0.71128 & -0.12 \\
CT & 0.350 & 0.276144 & 0.36 \\
FT & 0.295 & 0.221752 & -0.12 \\
ST & 0.355 & 1.046 & 1.01 \\
OT & 0.296 & 0.71128 & -0.67 \\
\hline
\end{tabular}


Table S7. Bonds

\begin{tabular}{|c|c|c|}
\hline Bond & Bond length (nm) & Force constant $\left(\mathrm{kJ} \mathrm{mol}^{-1} \mathrm{~nm}^{-2}\right)$ \\
\hline $\mathrm{CN}-\mathrm{ON}$ & 0.1410 & 267144.0 \\
\hline $\mathrm{CT}-\mathrm{ON}$ & 0.1410 & 267144.0 \\
\hline $\mathrm{CT}-\mathrm{FT}$ & 0.1332 & 307105.6 \\
\hline $\mathrm{CT}-\mathrm{CT}$ & 0.1529 & 224362.4 \\
\hline $\mathrm{CT}-\mathrm{ST}$ & 0.1810 & 185769.6 \\
\hline $\mathrm{ST}-\mathrm{OT}$ & 0.1440 & 585760.0 \\
\hline
\end{tabular}

Table S8. Bond angles

\begin{tabular}{|c|c|c|}
\hline Bond angle & Angle (deg) & Force constant $\left(\mathrm{kJ} \mathrm{mol}^{-1} \mathrm{rad}^{-2}\right)$ \\
\hline $\mathrm{CN}-\mathrm{ON}-\mathrm{CT}$ & 116.9 & 694.544 \\
\hline $\mathrm{ON}-\mathrm{CT}-\mathrm{FT}$ & 109.8 & 425.000 \\
\hline $\mathrm{ON}-\mathrm{CT}-\mathrm{CT}$ & 109.5 & 418.400 \\
\hline $\mathrm{CT}-\mathrm{CT}-\mathrm{CT}$ & 112.5 & 488.273 \\
\hline $\mathrm{CT}-\mathrm{CT}-\mathrm{FT}$ & 109.8 & 418.400 \\
\hline $\mathrm{FT}-\mathrm{CT}-\mathrm{FT}$ & 109.1 & 644.336 \\
\hline $\mathrm{CT}-\mathrm{ON}-\mathrm{CT}$ & 116.9 & 694.544 \\
\hline $\mathrm{CT}-\mathrm{CT}-\mathrm{ST}$ & 114.7 & 418.400 \\
\hline $\mathrm{CT}-\mathrm{ST}-\mathrm{OT}$ & 108.9 & 619.232 \\
\hline $\mathrm{FT}-\mathrm{CT}-\mathrm{ST}$ & 109.5 & 418.400 \\
\hline $\mathrm{OT}-\mathrm{ST}-\mathrm{OT}$ & 119.0 & 870.272 \\
\hline
\end{tabular}

Table S9. Dihedrals

Ryckaert-Bellemans functions were used for dihedrals

$$
V_{\text {dihe }}=\sum_{n=0}^{5} C_{n}(\cos (\psi))^{n}
$$

Where $\psi=\varphi-180^{\circ}$

\begin{tabular}{|c|c|c|c|c|c|c|}
\hline Dihedral & $\begin{array}{c}\mathrm{C}_{0} \\
\left(\mathrm{~kJ} \mathrm{~mol}^{-1}\right)\end{array}$ & $\begin{array}{c}\mathrm{C}_{1} \\
\left(\mathrm{~kJ} \mathrm{~mol}^{-1}\right)\end{array}$ & $\begin{array}{c}\mathrm{C}_{2} \\
\left(\mathrm{~kJ} \mathrm{~mol}^{-1}\right)\end{array}$ & $\begin{array}{c}\mathrm{C}_{3} \\
\left(\mathrm{~kJ} \mathrm{~mol}^{-1}\right)\end{array}$ & $\begin{array}{c}\mathrm{C}_{4} \\
\left(\mathrm{~kJ} \mathrm{~mol}^{-1}\right)\end{array}$ & $\begin{array}{c}\mathrm{C}_{5} \\
\left(\mathrm{~kJ} \mathrm{~mol}^{-1}\right)\end{array}$ \\
\hline $\mathrm{CN}-\mathrm{ON}-\mathrm{CT}-\mathrm{FT}$ & 0.239 & 0.717 & 0 & -0.956 & 0 & 0 \\
\hline $\mathrm{CN}-\mathrm{ON}-\mathrm{CT}-\mathrm{CT}$ & 0.239 & 0.717 & 0 & -0.956 & 0 & 0 \\
\hline $\mathrm{ON}-\mathrm{CT}-\mathrm{CT}-\mathrm{FT}$ & 0.239 & 0.717 & 0 & -0.956 & 0 & 0 \\
\hline $\mathrm{ON}-\mathrm{CT}-\mathrm{CT}-\mathrm{ON}$ & 0.239 & 0.717 & 0 & -0.956 & 0 & 0 \\
\hline $\mathrm{CT}-\mathrm{CT}-\mathrm{CT}-\mathrm{FT}$ & 0.985 & -2.956 & 0 & 3.941 & 0 & 0 \\
\hline $\mathrm{FT}-\mathrm{CT}-\mathrm{CT}-\mathrm{FT}$ & 0.966 & 2.898 & 0 & -3.865 & 0 & 0 \\
\hline $\mathrm{CT}-\mathrm{ON}-\mathrm{CT}-\mathrm{FT}$ & 0.239 & 0.717 & 0 & -0.956 & 0 & 0 \\
\hline $\mathrm{ON}-\mathrm{CT}-\mathrm{CT}-\mathrm{ST}$ & 0.239 & 0.717 & 0 & -0.956 & 0 & 0 \\
\hline $\mathrm{CT}-\mathrm{CT}-\mathrm{ST}-\mathrm{OT}$ & 0.239 & 0.717 & 0 & -0.956 & 0 & 0 \\
\hline $\mathrm{FT}-\mathrm{CT}-\mathrm{CT}-\mathrm{ST}$ & 0.239 & 0.717 & 0 & -0.956 & 0 & 0 \\
\hline $\mathrm{FT}-\mathrm{CT}-\mathrm{ST}-\mathrm{OT}$ & 0.239 & 0.717 & 0 & -0.956 & 0 & 0 \\
\hline
\end{tabular}




\section{Snapshot of ordered water in CNT}

(a)

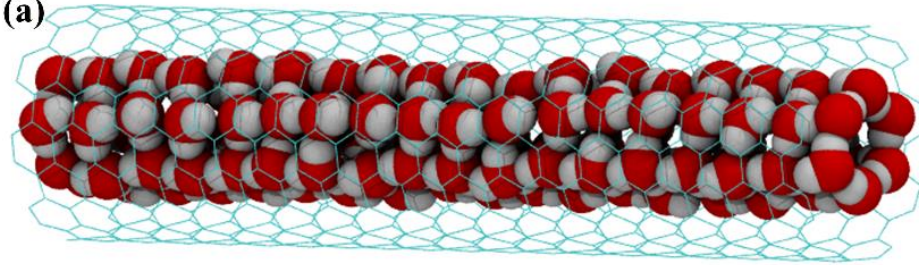

(b)

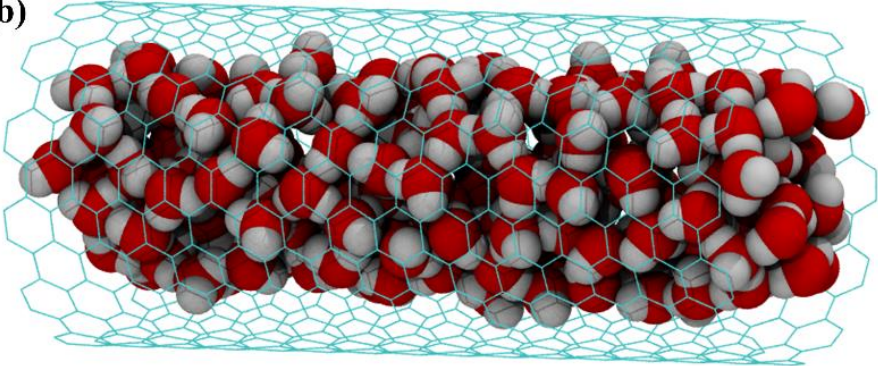

Figure S3. Ordered water (a) and disordered water (b) in a carbon nanotube. Panel (a) corresponds to a tube diameter of $1.248 \mathrm{~nm}$ and panel (b) corresponds to a tube diameter of $1.664 \mathrm{~nm}$. Water molecules form a hexagonal-like structure in (a) while distribute randomly in (b). 


\section{Potential energy of water in CNT model}

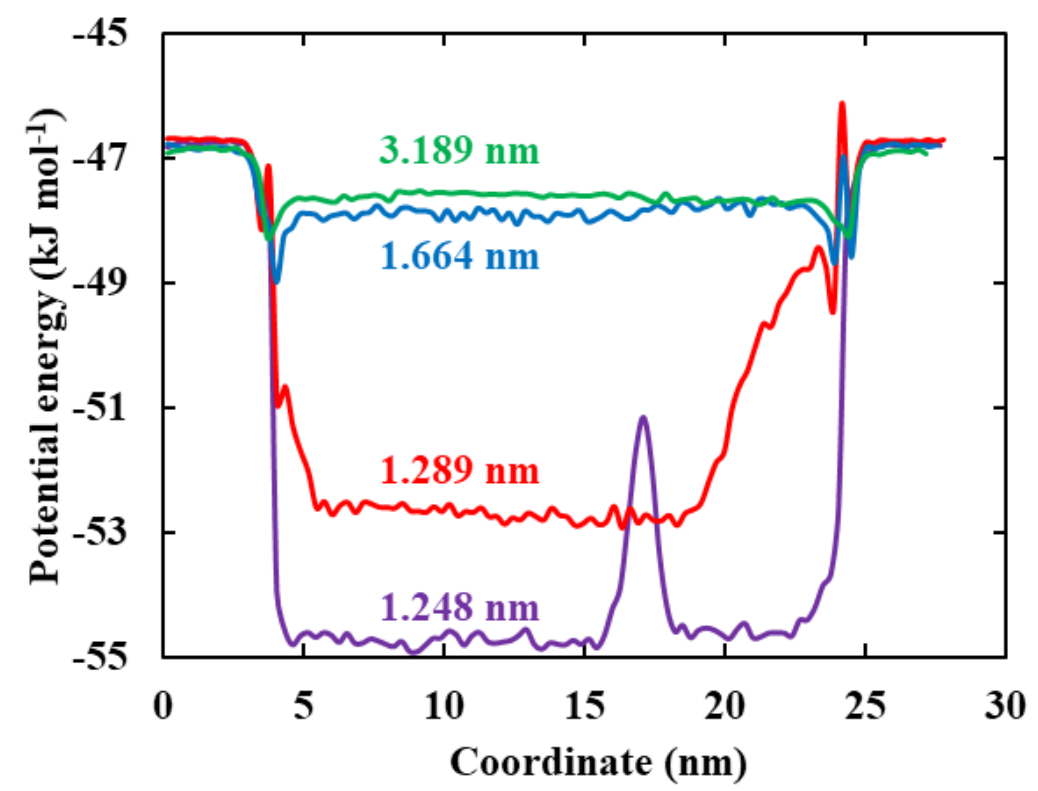

Figure S4. Potential energy of water molecules inside the CNT as a function of z-axis coordinate. The potential energy plots correspond to CNT models of different diameters as labeled on the plots. Potential energy is calculated by adding up intermolecular interactions with a cut-off distance of $2.4 \mathrm{~nm}$. Longrange electrostatic interactions, which do not contribute significantly to the total potential energy in these systems, are ignored. The two "arms" on each side of every plot correspond to the potential energy of the water reservoir. Ordered water is present in the CNTs with diameters of $1.248 \mathrm{~nm}$ and $1.289 \mathrm{~nm}$. The potential energy of ordered water is smaller than that of disordered water. Note that the potential energy of the ordered water in CNT is not homogeneous. In 1.248-nm case, a sharp increase in potential energy presents around $17 \mathrm{~nm}$ in the $\mathrm{z}$ axis, which corresponds to a defect in the ordered water inside the CNT. Defects also present in the 1.289-nm CNT. The existence of these imperfections, which destabilize the ordered water structure, are most likely responsible for the non-zero diffusion coefficient of ordered water.

\section{Equilibration of dispersed system towards phase-separated system}


$\lambda=4$
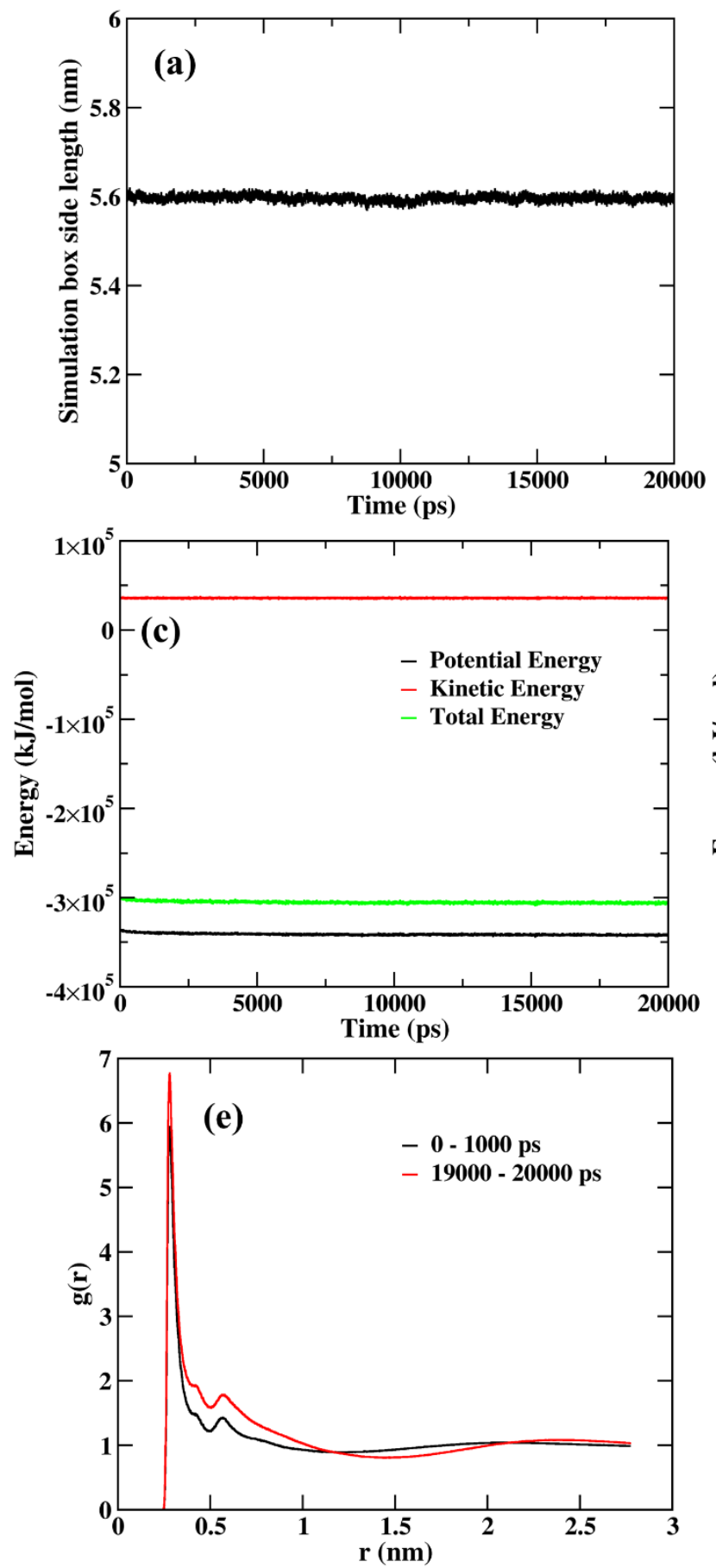

$\lambda=15$
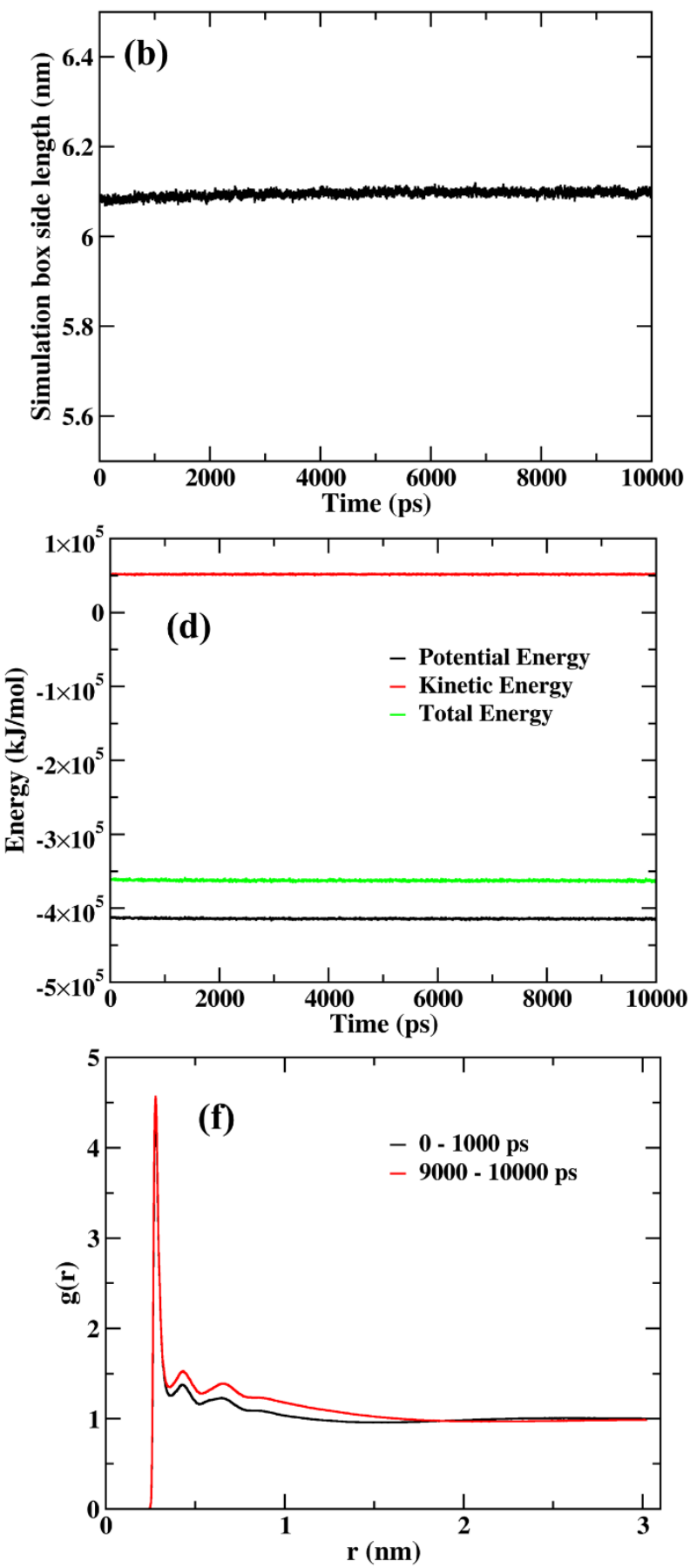

Figure S5. Change of simulation box size, system energies, and radial distribution functions during equilibration of dispersed system at $\lambda=4(\mathrm{a}, \mathrm{c}, \mathrm{e})$ and $\lambda=15(\mathrm{~b}, \mathrm{~d}, \mathrm{f})$. The transition to phase-separated system does not lead to significant change of density $(a, b)$ or energies $(c, d)$. The radial distribution 
functions $(\mathrm{e}, \mathrm{f})$ indicate water molecules are seeing more neighboring water molecules after phase separation.

\section{Density heterogeneity in mixture of sidechains and water molecules}
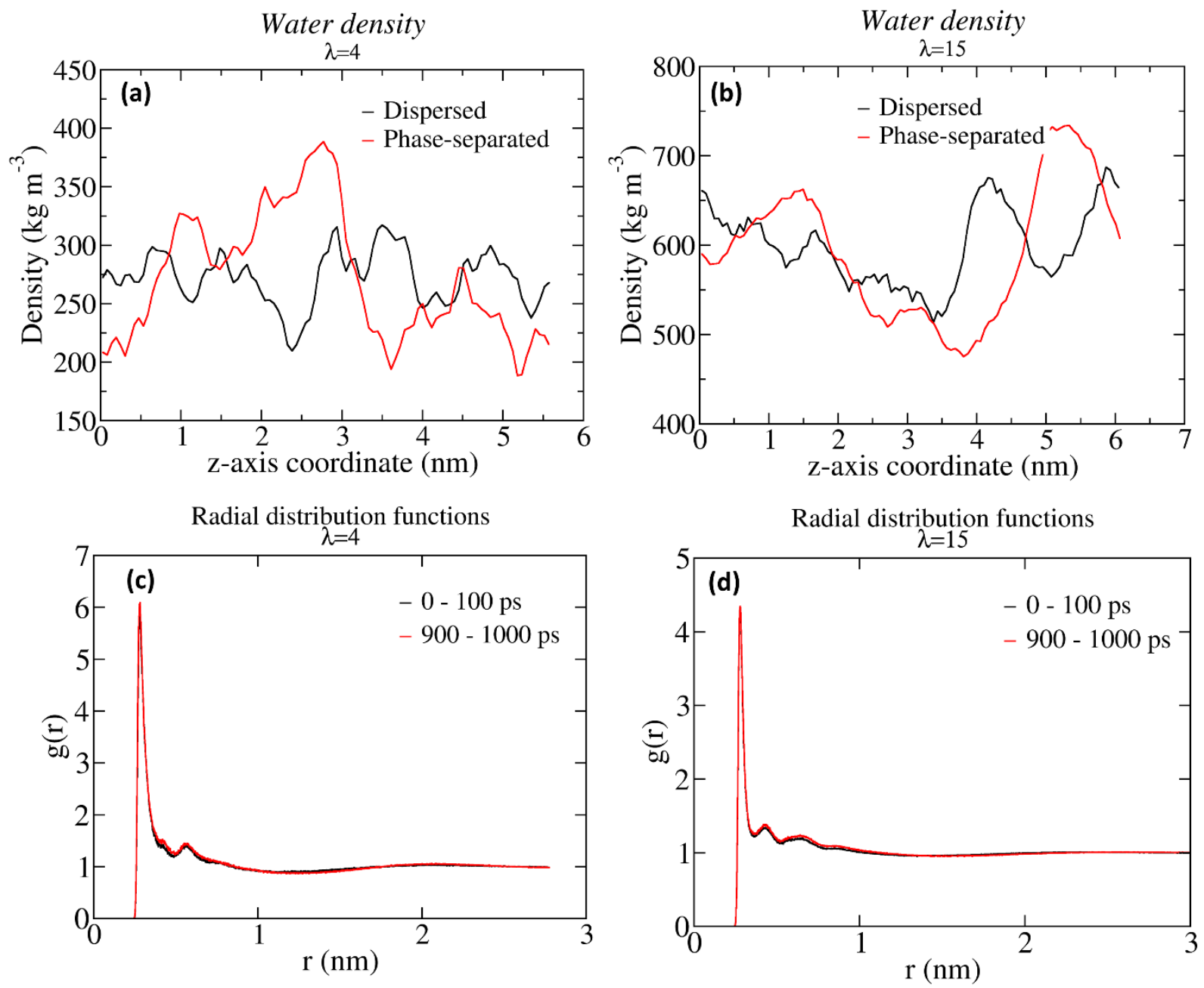

Figure S6. Water density in dispersed system and phase-separated system at $\lambda=4$ (a) and $\lambda=15$ (b).

Sidechains are free in all scenarios. The dispersed system with free sidechains is in a metastable state. To keep the system as close to the initially dispersed state as possible, only the beginning $1 \mathrm{~ns}$ of the simulation is used in the calculation of density. Water density for the phase-separated system is calculated based on an 8 ns trajectory. While generated over a longer trajectory, the fluctuation of density in phaseseparated system is notably larger than that in dispersed system, signaling a larger structural heterogeneity 
composed of water-rich and water-poor domains. RDFs (between oxygen atoms of water molecules) calculated from the initial $100 \mathrm{ps}(0-100 \mathrm{ps})$ and the final $100 \mathrm{ps}(900-1000 \mathrm{ps})$ of the probed $1 \mathrm{~ns}$ are shown for $\lambda=4$ (c) and $\lambda=15$ (d). During $1 \mathrm{~ns}$, the change of RDFs is limited which indicates the change of local environment is small.

\section{The front factor $\ln \mathrm{D}_{0}$ from Arrhenius fits}
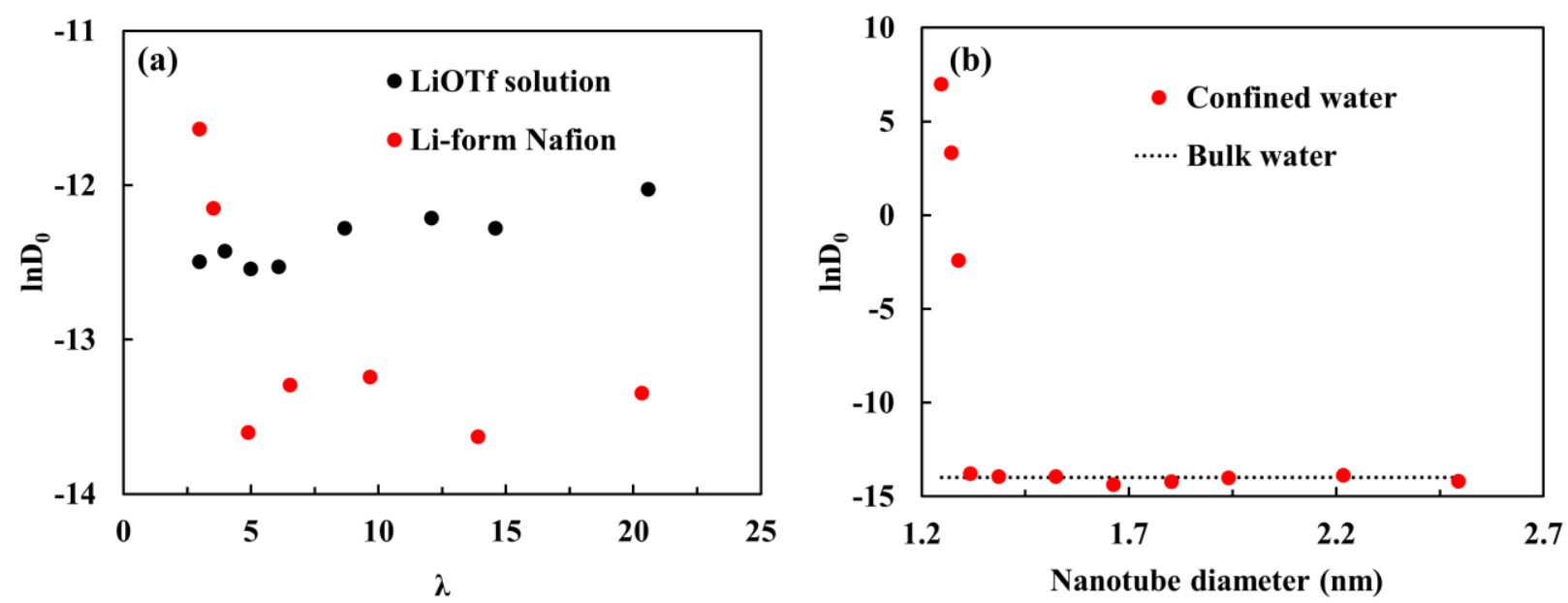

Figure S7. The pre-exponential factor $\ln \mathrm{D}_{0}$ from the Arrhenius equation for diffusometry experiments and MD simulations. Panel (a) corresponds to the results from experimental measurements of lithium triflate solutions and lithium-form Nafion. Panel (b) corresponds to simulations of confined water in CNT and of bulk water. We will explain the detailed physical interpretation of $\mathrm{D}_{0}$ in an upcoming publication. 